\title{
Chemical Plant Relocation and Route Reassignment Models
}

\author{
X.L. Zhu \\ College of Arts and Sciences \\ Shanghai Maritime University \\ Shanghai, China
}

\begin{abstract}
Based on facility location and route assignment model, several multi-objective optimization models for chemical plant relocation are established. There are four main objectives: minimum risk, maximum utilization of the original transportation network, minimum cost, and minimum distance for relocation. Two kinds of mathematical model are presented: the arc-model using the flows on arcs as decision variables and the routemodel using the route flows as decision variables. The multi-objective models are transformed into single objective models in which risk is minimized while constraints are imposed on the utilization, cost and distance. Arc-model is easy to be solved and the solution of route-model can clearly show the routes of transporting chemical products. The numerical results are promising.
\end{abstract}

Keywords-relocation; multi-objective optimization; hazardous materials transportation; Integration optimization

\section{INTRODUCTION}

The Qingdao oil pipeline explosion which occurred on November 22nd 2013 in China, caused a total of 62 people were killed, 136 injured. The direct economic loss was 0.75 billion yuan, equivalent to about $\$ 0.13$ billion. In addition, the road surface was covered in leaked oil and seawater was contaminated by crude oil. Unfortunately, in less than one year, on June 30th, Dalian oil pipeline exploded. The two serious accidents clearly show that the consequence is profound once the chemical products are accident. It will not just bring a direct loss of life and property, but cause the damage to environment.

Safety of chemical products has attracted increasing attention from the general public and people have concerned more and more about transporting chemical products and locating the chemical plant. There are many mathematical models to solve the problems caused by hazardous materials (hazamat). Discrete location-routing model is typical, and quite a few models solving methods have been developed [19]. Erkut [1] had an in-depth discussion on the hazamat transportation problems, especially on the risk assessment to the path, and created several models. These models can be divided into two groups: the arc form models where arc flows are decision variables and the route form models where path flows are decision variables. Solving methods are mainly based on the general multi-objective programming theory, such as finding Perreto equilibrium solution and searching elite solutions using heuristic algorithm. Other studies [3-4] established the bi-level programming models for routing allocation of hazamat transportation problems, without considering the location, in which the bi-level programming was transformed into a single layer by using the KKT conditions and duality theory of underlying extreme point.

However, relocation is not considered in these works [19]. This paper focuses mainly on the relocation problem. Compared with the location problem, in this problem routes are extracted the maximum from original ones and reassigned, with the relocation distance as short as possible.

\section{MATHEMATICAL FORMULATION}

With the development of modern economy, especially the rapid development of regional urbanization, in a few years the suburbs often become high-rise buildings everywhere. A certain chemical plant might be located in remote suburban decades ago and in the past the transportation routes to demand point are safe obtaining policy allows. But now the surrounding environment of old plants has undergone great changes, the regional traffic network and traffic laws have also been changed.

Under the above background, the relocation of the chemical plant needs to be considered. Naturally, the plant's decision makers certainly hope that the new site is near the old one, because the cost can be saved and it is conducive to their commercial trade. Moreover, regional economy and population development, and even the original transport paths in some sections are not allowed to transport hazamat, then new transport routes based on original routes have to be reconsider as soon as possible.

The following assumptions are made.

Assumption 1: Single plant relocation and single chemical product are considered in the paper.

Assumption 2: Consider routes from the plant to demand nodes of shipped products, without regard to the return route.

Assumption 3: All nodes are candidates for the new site, the original transport routes and the flows covered the routes are known.

Assumption 4: The transportation network from the chemical plant to the demand node is known. 
Assumption 5: Cost and risk of per unit product covered on each arc in the transportation network are known. This assumption is reasonable, see [9].

TABLE I. MATHEMATICAL NotATION.

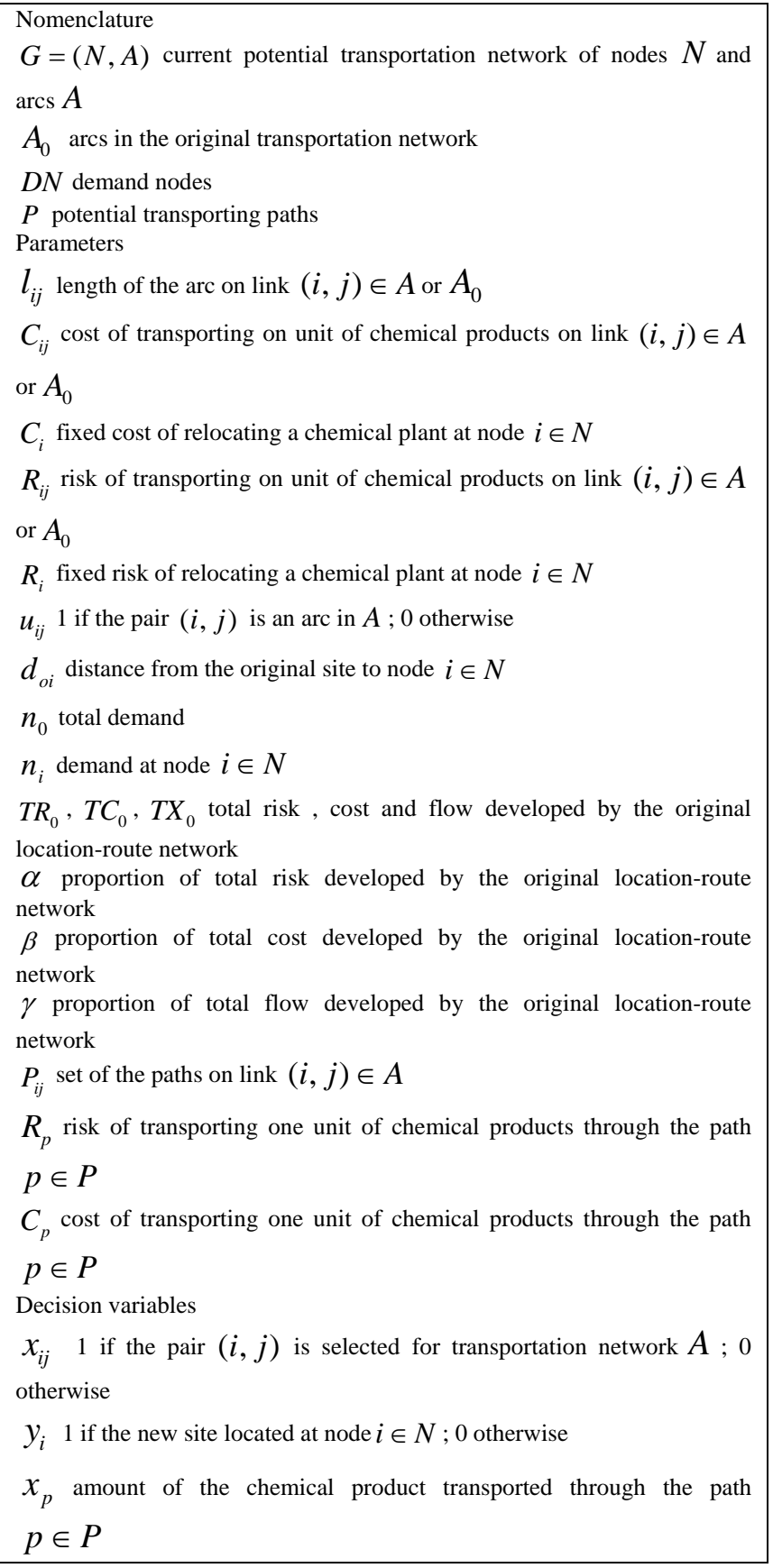

A. Arc-model

Model I:

$\min \sum_{(i, j) \in A} X_{i j} l_{i j} R_{i j}+\sum_{i \in N} R_{i} y_{i}$

$$
\begin{aligned}
& \max \sum_{(i, j) \in A_{0}} x_{i j} l_{i j} \\
& \min \sum_{(i, j) \in A} x_{i j} l_{i j} C_{i j}+\sum_{i \in N} C_{i} y_{i} \\
& \min \sum_{i \in N} y_{i} d_{o i}
\end{aligned}
$$

s.t.

$$
\begin{aligned}
& \sum_{j \in N} x_{i j}-\sum_{j \in N} x_{j i}=n_{0} y_{i}, i \notin D N \\
& \sum_{j \in N} x_{i j}-\sum_{j \in N} x_{j i}=n_{0} y_{i}-n_{i}, i \in D N \\
& \sum_{i \in N} y_{i}=1 \\
& 0 \leq x_{i j} \leq u_{i j}, \quad y_{i} \in \begin{cases}0,1\} .\end{cases}
\end{aligned}
$$

(8)

Four objective functions (1), (2), (3) and (4) focus on minimizing the total risk, maximizing the utilization of the original transportation network, and minimizing the total cost and the reassignment distance, respectively. Constrains (5) and (6) are the balance of flows and constraint (7) states new site unique.

The multi-objective model is transformed into single objective models, which are solved by the solver Lingo12. The mathematical model is as follows.

Model II:

$$
\begin{array}{ll}
\min & \sum_{i \in N} y_{i} d_{o i} \\
\text { s.t. } & (5),(6),(7),(8) \\
& \sum_{(i, j) \in A} x_{i j} l_{i j} R_{i j} \leq \alpha T R_{0} \\
& \sum_{(i, j) \in A} x_{i j} l_{i j} C_{i j} \leq \beta T C_{0} \\
& \sum_{(i, j) \in A_{0}} x_{i j} l_{i j} \geq \gamma T X_{0}
\end{array}
$$

According to the above model, the flow on each arc can be computed. However, if the network topology is more complex and more many nodes are involved, it is difficult to obtain clear routes of products transportation. Therefore, it is necessary to establish the following route-model.

\section{B. Route-Model}

The following mathematical model is proposed by modifying the location-routing mode from the reference [1].

Model III

$$
\begin{aligned}
& \min \sum_{p \in P} x_{p} R_{p} \\
& \max \sum_{(i, j) \in p \& \& p \in P} x_{p} l_{i j}
\end{aligned}
$$




$$
\begin{aligned}
& \min \sum_{p \in P} x_{p} C_{p} \\
& \min \sum_{i \in N} y_{i} d_{o i} \\
& \text { s.t. } \\
& \quad \sum_{i \in N} \sum_{p \in P_{i j}} x_{p}=n_{0} y_{i} \\
& \quad \sum_{i \in N} \sum_{p \in P_{i j}} x_{p}=n_{j}, j \in D N \\
& \quad \sum_{i \in N} y_{i}=1 \\
& \quad 0 \leq \sum_{(i, j) \in p \& \& p \in P} x_{p} \leq u_{i j}, y_{i} \in\{0,1\}
\end{aligned}
$$

Main algorithm:

To minimize the risk as the overall objective, the model is solved and different solutions are obtained by reducing cost rate, enhancing utilization rate of the old routes and shorting relocation distance. The algorithm steps in detail are stated in the following.

Step 1: Using the depth-first algorithm, seek all paths from each node to each demand node as well as the old site.

Step 2: Cost and risk of per unit product on each path is calculated and shortest distances are computed from each node to the old site. If there is no path between two nodes, set the shortest distance of them assigns a large number.

Step 3: The decision variables include the flow covered each route path and the binary variable which depends on whether the related node is selected as the new site. Based on the mathematical model, matlab programming is created for computing the coefficient vector of objective function and the coefficients matrix of constraints. Then, the solver Lingo12 solves the mixed integer programming problem.

Note: Finding all route paths from the new site to all demand nodes is a NP problem, so the above algorithm is only suitable for relatively small-scale network situation. If the network is large, it is recommended to use an intelligent algorithm, such as genetic algorithms or particle swarm algorithm etc.

\section{NUMERICAL TESTING}

The transportation network diagram for a chemical plant is as Figure 1.

In the following network, node 7 is the original site, and node 1,9 and 12 are the demand nodes and according demanding amounts are 2, 3 and 3, respectively. The original transport routes are $\{7,8,3,1\},\{7,9\}$ and $\{7,9,10,12\}$, respectively. The following table shows the risk, cost, length and flow limit

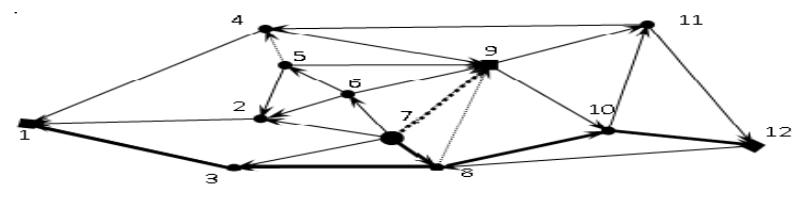

FIGURE I. TRANSPORTATION NET WORK FOR A CHEMICAL PLANT.

\section{The OlD Site $\quad$ DEMAND NOdE $\quad$ ORIGINAL TRANSPORT Route}

covered on each arc in the network. It is noted that the values of risk and cost are related to transporting one unit chemical products.

TABLE II. THE VALUE FOR RISK, COST, LENGTH AND FLOW LIMIT, RESPECTIVELY.

\begin{tabular}{|l|l|l|l|l|l|l|l|l|l|}
\hline arc & $\mathrm{R}$ & $\mathrm{C}$ & $\mathrm{L}$ & $\mathrm{U}$ & $\operatorname{arc}$ & $\mathrm{R}$ & $\mathrm{C}$ & $\mathrm{L}$ & $\mathrm{U}$ \\
\hline$(2,1)$ & 1 & 3 & 2 & 5 & $(12,8)$ & 1 & 2 & 4 & 5 \\
\hline$(3,1)$ & 1 & 2 & 2 & 5 & $(4,9)$ & 2 & 2 & 2 & 4 \\
\hline$(4,1)$ & 1 & 2 & 4 & 5 & $(5,9)$ & 3 & 3 & 2 & 4 \\
\hline$(5,2)$ & 4 & 3 & 1 & 4 & $(6,9)$ & 4 & 4 & 2 & 4 \\
\hline$(6,2)$ & 4 & 3 & 1 & 4 & $*(7,9)$ & 3 & 3 & 3 & 4 \\
\hline$(7,2)$ & 3 & 2 & 1 & 4 & $*(8,9)$ & 2 & 2 & 4 & 4 \\
\hline$(7,3)$ & 2 & 2 & 2 & 4 & $*(8,10)$ & 2 & 2 & 3 & 4 \\
\hline$(8,3)$ & 1 & 3 & 3 & 4 & $(9,10)$ & 2 & 2 & 2 & 4 \\
\hline$*(5,4)$ & 1 & 2 & 1 & 5 & $(9,11)$ & 1 & 1 & 2 & 5 \\
\hline$(11,4)$ & 1 & 3 & 4 & 5 & $(10,11)$ & 1 & 1 & 3 & 5 \\
\hline$(6,5)$ & 4 & 3 & 1 & 4 & $(10,12)$ & 1 & 1 & 1 & 5 \\
\hline$(7,6)$ & 4 & 4 & 1 & 3 & $(11,12)$ & 1 & 1 & 3 & 5 \\
\hline$(7,8)$ & 1 & 2 & 1 & 5 & & & & & \\
\hline
\end{tabular}

* The arc is to be banned the transport of the chemical product (but it is available for relocation).

Next, the relocation will be solved. The total risk, cost and flow developed by the original location-route network are obtained and $T R_{0}=111, T C_{0}=84$, and $T X_{0}=36$, respectively. The original transporting routes are known, i.e.

$$
A_{o}=\{(7,3),(3,1),(7,9),(7,8),(8,10),(10,12)\}
$$

Remain parameters are shown in the following table 3 and table 4 , and the main results are listed in the following table 5 .

TABLE III. THE DISTANCES FROM THE ORIGINAL SITE TO NODE $i \in N$

\begin{tabular}{|l|l|l|l|l|l|l|l|l|l|l|l|l|}
\hline$d_{\text {oi }}$ & $\mathrm{i}=1$ & 2 & 3 & 4 & 5 & 6 & 7 & 8 & 9 & 10 & 11 & 12 \\
\hline $\mathrm{o}=7$ & 3 & 1 & 2 & 3 & 2 & 1 & 0 & 1 & 3 & 4 & 5 & 5 \\
\hline
\end{tabular}

TABLE IV. THE DEMAND, FIXED RISK AND FIXED COST AT NODE $i \in N$

\begin{tabular}{|r|r|r|r|r|r|r|r|r|r|r|r|r|}
\hline$i$ & 1 & 2 & 3 & 4 & 5 & 6 & 7 & 8 & 9 & $\begin{array}{r}1 \\
0\end{array}$ & $\begin{array}{l}1 \\
2\end{array}$ \\
\hline$n_{i}$ & 2 & 0 & 0 & 0 & 0 & 0 & 0 & 0 & 3 & 0 & 0 & 3 \\
\hline$R$ & 1 & 4 & 4 & 2 & 4 & 6 & 4 & 1 & 4 & 2 & 1 & 1 \\
\hline$C$ & 1 & 5 & 5 & 2 & 4 & 7 & 0 & 1 & 5 & 3 & 1 & 1 \\
\hline
\end{tabular}


TABLE V. THE LIST OF THE MAIN RESULTS

\begin{tabular}{|c|c|c|c|}
\hline $\mathrm{e}^{\text {Objectiv }}$ & $\begin{array}{l}\text { New site } \\
\text { (distance) }\end{array}$ & Route(flow) & $\begin{array}{l}\text { Risk } \\
\text { (rate \%) }\end{array}$ \\
\hline $\begin{array}{l}\text { Minimum } \\
\text { risk }\end{array}$ & $\begin{array}{l}11 \\
\text { (5) }\end{array}$ & $\begin{array}{ll} & 11 \rightarrow 4 \rightarrow 1(2) \\
\rightarrow 9(3) & 11 \rightarrow 4 \\
11 \rightarrow 12(3) & \end{array}$ & $\begin{array}{l}57 \\
(-8.6 \%)\end{array}$ \\
\hline $\begin{array}{l}\text { Maximum } \\
\text { utilization }\end{array}$ & $\begin{array}{l}10 \\
(4)\end{array}$ & $\begin{array}{l}10 \rightarrow 12 \rightarrow 8 \rightarrow 3 \rightarrow 1(2) \\
10 \rightarrow 11 \rightarrow 4 \rightarrow 9(3) \quad 10 \\
\rightarrow 12(3)\end{array}$ & $\begin{array}{l}72 \\
(-5.1 \%)\end{array}$ \\
\hline $\begin{array}{l}\text { Minimum } \\
\text { cost }\end{array}$ & $\begin{array}{l}9 \\
(3)\end{array}$ & $\begin{array}{l}9 \rightarrow 11 \rightarrow 4 \rightarrow 1(2) \\
9 \rightarrow 10 \rightarrow 12(3) \quad 9 \rightarrow 9(3)\end{array}$ & $\begin{array}{l}83 \\
(-5.2 \%)\end{array}$ \\
\hline $\begin{array}{l}\text { Minimum } \\
\text { distance }\end{array}$ & $\begin{array}{c}6 \\
(1)\end{array}$ & $\begin{array}{l}6 \rightarrow 2 \rightarrow 1(2) \quad 6 \rightarrow 5 \rightarrow \\
9(2) \\
6 \rightarrow 9(1) \quad 6 \rightarrow 9 \rightarrow 10 \rightarrow \\
12(3)\end{array}$ & $\begin{array}{l}137 \\
(+23.4 \%)\end{array}$ \\
\hline other & $\begin{array}{l}11 \\
(5)\end{array}$ & $\begin{array}{l}11 \rightarrow 12 \rightarrow 8 \rightarrow 3 \rightarrow 1(2) \\
11 \rightarrow 4 \rightarrow 9(3) \quad 11 \rightarrow \\
12(3)\end{array}$ & $\begin{array}{l}65 \\
(-1.4 \%)\end{array}$ \\
\hline & $\begin{array}{l}\text { Utilization } \\
\text { (rate \%) }\end{array}$ & $\begin{array}{l}\text { Total cost } \\
\text { ( transportation cost, } \\
\text { rate) }\end{array}$ & Remark \\
\hline $\begin{array}{l}\text { Minimum } \\
\text { risk }\end{array}$ & 0 & $105(97,+15.5 \%)$ & $\begin{array}{l}0 \\
\text { utilization }\end{array}$ \\
\hline $\begin{array}{l}\text { Maximum } \\
\text { utilization }\end{array}$ & 15(41.7\%) & $128(104,+23.8 \%)$ & \\
\hline $\begin{array}{l}\text { Minimum } \\
\text { cost }\end{array}$ & $3(8.3 \%)$ & $99(59,-29.8 \%)$ & $\begin{array}{l}\text { demand } \\
\text { node is } \\
\text { new site }\end{array}$ \\
\hline $\begin{array}{l}\text { Minimum } \\
\text { distance }\end{array}$ & $13(36.1 \%)$ & $130(74,-11.9 \%)$ & \\
\hline other & $10(27.8 \%)$ & $113(105,+25 \%)$ & \\
\hline
\end{tabular}

The calculation results show that the original routes are completely obsolete if minimizing the risk is just considered, which means that all transporting routes are needed to regain licenses and will increase the extra time cost and expense cost. Whereas, if just taking the shortest distance to the location (node 6), it is obvious to increases the risk in great quantities and costs, which is not conducive to the long-term development of the plant. If node 11 is as the new site, though both the risk value and the old path utilization rate will be higher, the cost will increase and the reassignment distance will be longer.

\section{CONCLUSIONS}

In this paper, chemical plant relocation problem is discussed, the new site selection and new routing reassignment are mainly computed so as to minimize the risks covered and maximize the utilization of old routes due to the risk of chemical products transportation and the hazamat transportation regulations. In addition, the lowest possible cost and the shortest distance relocation are also concerned. According to these ideas, three multi-objective optimization models are proposed and different solutions were discussed.

It should be noted that here the relocation problem is discussed only in relative simple cases. In fact, a large chemical plant often produces a variety of chemical products, and its mode of transport is varied, and its cost calculation is complex. Forever, because the location routing problem is a
NP problem, when the network size is large it is difficult to have a better way to obtain the ideal solution. All these show that the problem remains to be thorough, this is just the beginning.

\section{ACKNOWLEDGMENTS}

This study was supported by grants from the National Natural Science Foundation of China (Nos. 11101266, 11071159 and 11301334) and the Shanghai Science and a project of administrated by Technology Committee project (No. 12510501700). I thank the conference's anonymous reviewers for their valuable comments and suggestions, which help to improve my paper.

\section{REFERENCES}

[1] Erhan Erkut \& Osman Alp, Desiging a road network for hazardous materials shipments. Computers \& Operations Research, 34(2007), pp.1389-1405, 2007.

[2] Erhan Erkut \& Fatma Gzara, Solving the hazmat transport network design problem. Computers \& Operations Research, 35(2008), pp.2234-2247, 2008.

[3] Patrice Marcotte, Anne Mercier, Gilles Savard \& Vedat Verter, Toll Policies for Mitigating Hazardous Materials Transport Risk. Transportation Science, 43(2), pp. 228-243, 2009.

[4] Bahar Y. Kara and Vedat Verter, Designing a Road Network for Hazardous Materials Transportation. Transportation Science, 38(2), pp. 188-196, 2004.

[5] Linglin Ni \& Feng Shi, Hub location and allocation optimization of multiple allocation hub-and-spoke express networks. Systems Engineering-Theory \& [1] Practice, 32(2), pp. 441-448, 2012.

[6] Hanyan Wang \& Qishan Zhang, Multi-objective optimization of periodic location routing problem for waste logistics network in cities. Systems Engineering-Theory \& Practice, 33(8), pp. 1998-2006, 2013.

[7] Jun Zhao, Yu Li \& Qiyuan Peng, Integrated optimization of location \& task division of passenger stations in railway terminal. Journal of the China Railway Society, 32(6), pp. 9-18, 2010.

[8] Bo He, Chao Yang \& Mingming Ren, Undesirable facility location problem using a multi-objective evolutionary algorithm, Systems Engineering-Theory \& Practice, 11, pp. 72-77, 2007.

[9] Jun Li, Xiaolin Guo, Hang Wei \& Jibing Li, Research on the transport of hazardous materials, Science Press: Beijing, 2010. 